\title{
Lutas e resistências quilombolas no Brasil: um debate fundamental para o Serviço Social
}

Quilombola struggles and resistance in Brazil: a fundamental debate for Social Work

\author{
Maria Raimunda Penha Soares*
}

\begin{abstract}
Resumo - A partir de uma perspectiva crítica, este artigo apresenta alguns elementos para o debate sobre lutas e resistências quilombolas no Brasil, a partir de uma perspectiva crítica, entendendo-as como movimentos contestatórios às diversas formas de opressão e exploração contemporâneas. Sinaliza, por outro lado, que a "liberdade" conquistada pelos negros com a Abolição, em 1888, não se efetivou em termos de acessos a direitos básicos ou reparações históricas, o que cria desigualdades raciais que estão na base da sociedade brasileira. Este trabalho também reúne elementos para o debate sobre os quilombos na contemporaneidade e as expressões da questão social nas comunidades quilombolas como locus de práticas interventivas do assistente social. Por fim, aponta que as lutas quilombolas contra o sistema de outrora podem ser referência para fortalecer ações anticapitalistas contemporâneas, reafirmando a importância do estudo dessas lutas para o debate na área de Serviço Social.
\end{abstract}

Palavras-chave: luta de classes; comunidades quilombolas; Serviço Social.

\begin{abstract}
This article presents a debate from a critical perspective on quilombola struggles and resistances in Brazil. These struggles are understood as contesting movements against different forms of contemporary oppression and exploitation. It also points out that the "freedom" black people conquered with 1888's abolition of slavery in Brazil didn't come true in terms of access to basic rights or historical reparation, which created the racial inequality at the core of Brazilian society. This paper also gathers elements for the debate on quilombos in the present day, and the expressions of the social issue in quilombola communities as a locus for social workers' interventionist practices. Finally, the article points out that quilombola struggles against the old system can serve as a reference to reinforce contemporary anti-capitalist actions, reasserting the importance of studying these struggles for the debate in the field of social work.

Keywords: class struggle; quilombola communities; Social Work.
\end{abstract}

\footnotetext{
*Assistente Social e Economista. Mestre e Doutora em Serviço Social pela ESS/UFRJ. Pós-doutorado pelo PPGPP/ UFMA. Professora Associada do Curso de Serviço Social da UFF/Campus de Rio das Ostras. Coordenadora do NEAB/ UFF/Campus de Rio das Ostras. E-mail: raysoares2411@gmail.com. ORCID: https://orcid.org/0000-0003-3360-7207.
} 


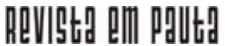

\} LUTAS E RESISTÊNCIAS - SOARES, M. R. P. \}

DOI: $10.12957 /$ REP.2020.52007

\section{Introdução}

Nos últimos anos temos presenciado um avanço significativo na produção teórica sobre a questão étnico-racial no Brasil. O aumento, ainda pequeno, mas importante, de docentes que se autodeclaram negros e direcionam suas pesquisas para essa área, a maior inserção de estudantes negros nas universidades e a militância de movimentos de mulheres negras e de coletivos de jovens de periferias, dentre outras mobilizações, indicam que há uma necessidade pulsante de lançar luz à realidade social dos negros e negras brasileiros, em especial, os que têm sido alvo de um genocídio histórico; e de combater o racismo, que ainda atravessa, de forma estrutural, as relações sociais.

O estudo crítico da questão étnico-racial indica que o racismo estrutural e as desigualdades raciais no Brasil contam com suas bases históricas localizadas no período de escravidão. Não há mais como negar a urgência em nos apropriarmos, no Serviço Social, de uma análise que elucida a formação sócio-histórica do país a partir do que, de fato, representaram quase 400 anos de escravidão para a constituição das relações sociais contemporâneas e o lugar da resistência negra.

A escravidão não foi uma relação de exploração e opressão que se sustentou sem lutas, de diversas formas e alcances. Esse resgate histórico implica apreender o homem negro e a mulher negra escravizados como sujeitos da resistência e da luta contra a exploração, contribuindo com a construção de um referencial identitário para trabalhadores negros que os inclua.

O Serviço Social brasileiro, por sua vez, possui um projeto profissional que se construiu a partir da afirmação de um referencial teóricometodológico marxista e de uma direção ético-política comprometida com a luta da classe trabalhadora. Apesar de o código de ética do Serviço Social de 1993 reafirmar o combate a toda forma de opressão e discriminação e de as diretrizes curriculares da Associação Brasileira de Ensino e Pesquisa em Serviço Social (Abepss), datadas de 1996, indicarem a incorporação de conteúdos sobre etnia e raça nos currículos, é notório que há uma lacuna ${ }^{1}$ no que tange ao estudo da questão étnico-racial brasileira na formação profissional em Serviço Social.

É importante destacar que essa carência não é uma característica da formação exclusiva dessa área, mas atravessa o ensino brasileiro e reflete um projeto de educação elitista construído desde o ensino básico, a partir de narrativas da classe dominante, que sustenta seus interesses econômicos e políticos. Em que pese, portanto, a contribuição de pesquisadores que vêm estudando e produzindo sobre a questão étnico-racial e o Serviço Social, do ponto de vista da nossa formação profissional e de nossas práticas

${ }^{1}$ Ver: Rocha (2009). 


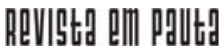

\} LUTAS E RESISTÊNCIAS - SOARES, M. R.P. \}

DOI: $10.12957 /$ REP.2020.52007

interventivas, ainda há muito em que avançarmos, sobretudo, com a apropriação do debate acerca das questões étnico-raciais como estruturantes nas relações sociais capitalistas no Brasil.

Em sintonia com as discussões contemporâneas e com as pautas atuais dos movimentos que se organizam a partir do combate às diversas formas de opressão e exploração capitalista, o conjunto formado pelos Conselhos Federal e Regionais de Serviço Social (CFESS/Cress) tem lançado, nos últimos anos, campanhas e resoluções de combate ao racismo e de orientação à categoria no sentido de construir intervenções profissionais antirracistas e contrárias a qualquer forma de preconceito e opressão. $\mathrm{Na}$ mesma direção, as diretrizes curriculares da Abepss $(1996$, p. 7) indicam a necessidade de "apreensão crítica do processo histórico como totalidade" e de "investigação sobre a formação histórica e os processos sociais contemporâneos que conformam a sociedade brasileira", com a perspectiva de "apreender as particularidades da constituição e desenvolvimento do capitalismo e do Serviço Social no país". Estas proposições convergem com a orientação atual da Abepss, presente no documento Subsídios para o debate sobre a questão étnico-racial na formação em Serviço Social, que indica como central "o compromisso na construção de um projeto de formação profissional antirracista e reconhece o significado socio-histórico do debate étnico-racial para o Serviço Social brasileiro" (ELPIDIO; ROCHA, 2018, p. $3)$.

A Abepss cumpre um papel essencial neste momento, o de fomentar o debate sobre as discussões de etnia e raça na formação em Serviço Social como estruturantes (em sua intersecção com as questões de gênero e classe) das relações sociais. Isto implica incluir tal questão sem fragmentála, sem encerrá-la em uma ou duas disciplinas, mas como debate que passa a ser central no entendimento das diversas expressões da questão social e, portanto, nas práticas interventivas profissionais. Os subsídios apresentados pela Abepss apontam para um desafio na formação profissional e as propostas que surgirem daí não devem ignorar o que já se encontra em produção, experimentação e construção a partir do ensino, de grupos e de núcleos de pesquisa e extensão dentro de cursos de Serviço Social, em diversas universidades brasileiras.

A inserção do debate sobre a questão étnico-racial no currículo possibilitará um salto qualitativo na formação em Serviço Social e na consolidação de um projeto profissional crítico. Por outro lado, possibilitará também a abertura de um campo de diálogo com movimentos sociais dentro e fora das universidades que têm pautado a luta antirracista, contra a criminalização da pobreza, o extermínio da juventude negra da periferia, o racismo e a intolerância religiosa - bandeiras necessárias a serem assumidas e articuladas com ações anticapitalistas na luta de classes contemporânea.

Neste artigo, apresentamos alguns elementos para entendermos como a luta atual dos quilombolas no Brasil se insere no contexto da luta 


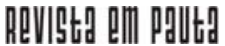

\} LUTAS E RESISTÊNCIAS - SOARES, M. R. P. \}

DOI: $10.12957 /$ REP.2020.52007

anticapitalista. Estas reflexões surgem a partir da realização de pesquisa e extensão, desde 2014, no Quilombo de Machadinha, na região Norte Fluminense (RJ), e em 2019 com o pós-doutorado realizado no Programa de Pós-Graduação em Políticas Públicas/UFMA (PPGPP), com pesquisa junto a quilombos que vêm sendo impactados pelo avanço do capital em seus territórios (através da duplicação de estradas, construção de portos privados, linhões de transmissão de energia, mineração etc.).

Tanto no Quilombo Machadinha quanto nos quilombos do Maranhão (Cedro, Santo Antônio e Carionguinho) as pesquisas foram realizadas a partir da metodologia de pesquisa-ação, o que nos permitiu, além da apreensão da realidade, desenvolver ações que emergiram da nossa inserção nos territórios. No Quilombo Machadinha realizamos pesquisa sobre a dinâmica de organização política e cultural de seus moradores atuando no projeto "Territórios Criativos (de 2015 a 2017, uma parceria do MEC/UFF) e integramos equipe de pesquisadores que atua junto à comunidade na implementação da Educação Escolar Quilombola. Nos quilombos do Maranhão, a pesquisa sobre "A liderança de mulheres quilombolas na organização política, social e cultural de suas comunidades" nos permitiu elaborar, com outros pesquisadores, os históricos de quatro comunidades, para fins de certificação junto à Fundação Cultural Palmares. Sustentamos, por fim, que a compreensão da luta quilombola outrora como resistência à escravidão e atualmente como resistência ao capitalismo, pode contribuir para novas formas de organização e mobilização da classe trabalhadora no Brasil.

\section{Os quilombos e a luta contra a escravidão no Brasil}

O estudo crítico da questão étnico-racial no Brasil implica a compreensão de que os quase 400 anos de Escravidão relegaram ao país elementos estruturais para a constituição do que consideramos posteriormente como questão social brasileira, entendida como o conjunto das desigualdades resultante da contradição capital/trabalho. Ou, como indica lamamoto (2009, p. 27), "[...] o conjunto das expressões das desigualdades da sociedade capitalista madura [...]". Desta forma, se a questão social surge com o capitalismo maduro, suas bases históricas, no Brasil, comportam elementos que antecedem o processo de industrialização, que ocorreu no país conservando valores escravocratas, os quais, a princípio, pareciam anacrônicos aos "padrões de modernização".

Uma contribuição importante para pensar esta relação entre modernidade/capitalismo e colonização das Américas é o conceito de colonialidade do poder, de Anibal Quijano (2005). Para Quijano (2005, p. 117), 
A globalização em curso é, em primeiro lugar, a culminação de um processo que começou com a constituição da América e do capitalismo colonial/moderno e eurocentrado como um novo padrão de poder mundial. Um dos eixos fundamentais desse padrão de poder é a classificação social da população mundial de acordo com a ideia de raça, uma construção mental que expressa a experiência básica da dominação colonial e que desde então permeia as dimensões mais importantes do poder mundial, incluindo sua racionalidade específica, o eurocentrismo.

Dessa forma, consideramos fundamental apreender a Escravidão nas Américas a partir do processo de acumulação primitiva do capital, o que, no nosso entendimento, oferece elementos para compreendermos criticamente a relação posterior, entre capitalismo, desigualdades raciais e racismo.

Por outro lado, a história sobre o período colonial e a escravidão no Brasil deve considerar e partir do estudo da luta e da resistência dos negros contra a escravidão, em especial, na formação dos quilombos, por serem estas também bases históricas fundamentais de constituição da questão social nestes trópicos. Atualmente já há uma importante produção sobre a história da resistência negra e quilombola no país, entretanto, ainda não foi incorporada na formação em Serviço Social.

Para Marx (1998, p. 828) "A chamada acumulação primitiva é apenas o processo histórico que dissocia o trabalhador dos meios de produção" e se efetiva "[...] pela conquista, pela escravização, pela rapina e pelo assassinato, em suma, pela violência". Segundo Ianni (1978), a acumulação primitiva do capital foi um processo de âmbito estrutural e internacional gestado pelo capital comercial. Desta forma, as colônias do novo mundo foram vitais para a acumulação de capitais em países europeus, principalmente na Inglaterra, onde, de acordo com lanni (1978, p. 6), "o escravo, negro ou mulato, índio ou mestiço, esteve na origem do operário". Portanto não se pode entender o processo de acumulação primitiva sem a anexação das Américas e a escravidão, nem tampouco a escravidão sem estar articulada ao surgimento do capitalismo. De acordo com Marx (1998, p. 864),

As descobertas de ouro e prata na América, o extermínio, a escravização das populações indígenas, forçadas a trabalhar no interior das minas, o início da conquista e pilhagem das Índias Orientais e a transformação da África num vasto campo de caçada lucrativa são os acontecimentos que marcam os albores da era da produção capitalista. Esses processos idílicos são fatores fundamentais da acumulação primitiva.

A acumulação primitiva do capital, que lança mão da violência para "forjar" o trabalhador assalariado na Europa, com os cercamentos, a rapina e a legislação sanguinária, dentre outras medidas, cria também, nas 


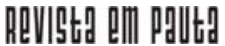

\} LUTAS E RESISTÊNCIAS - SOARES, M. R. P. \}

DOI: $10.12957 /$ REP.2020.52007

Américas, o extermínio dos seus povos nativos e a escravidão moderna de negros e negras trazidos do continente africano. Não podemos apreender as desigualdades raciais, o racismo estrutural e institucional no Brasil e sua funcionalidade ao capitalismo sem a análise crítica desse "legado histórico" do escravismo. Do mesmo modo, as bases históricas da questão social brasileira encontram-se na forma como os negros e negras recém-libertos foram lançados à própria sorte, sem políticas públicas que responsabilizassem o Estado pela inserção deles na sociedade do trabalho "livre". Os determinantes étnico-raciais estão, portanto, na base da problemática social brasileira.

Cabe ressaltar que a retomada do debate sobre a acumulação primitiva do capital, com o aporte dos elementos de gênero e raça, é elucidativa para compreendermos como o capital avança hoje sobre territórios quilombolas, indígenas e ribeirinhos, dentre outros considerados tradicionais, a partir de um processo que Harvey (2005) denomina de acumulação via espoliação. Para Harvey (2005, p. 121), a acumulação por espoliação consiste na reedição constante e em territórios específicos da acumulação primitiva, com todas as suas características, roubo, rapina, assassinato, sendo que "o Estado, com seu monopólio da violência e suas definições da legalidade, tem papel crucial no apoio e na promoção desses processos".

Clóvis Moura (1993) indica a necessidade de estudar e desvelar a questão étnico-racial no Brasil para adentrarmos nas particularidades das relações sociais capitalistas brasileiras. Conforme afirma Moura (1993, p. 8), é a "sociabilidade" criada na escravidão que direciona, em grande medida, "o tipo de desenvolvimento subsequente de instituições, de grupos e de classes, após a Abolição". Para o autor, sem o entendimento desta sociabilidade não é possível compreender o racismo no Brasil, tampouco construir formas de luta que o superem.

A luta contra a escravidão ocorreu a partir da organização de grupos de negros e negras em busca da liberdade, fugindo, criando quilombos, sabotando as plantações, formulando ou participando de insurreições armadas, contestando o sistema escravista e se contrapondo por meio destas organizações a este sistema (MOURA, 1992). Para este intelectual, a ausência da perspectiva de superação do sistema escravista nas lutas quilombolas não elimina destas seu caráter contestatório, mostrando o seu significado como um momento importante do antagonismo de classes.

A resistência negra implica um movimento muito mais amplo, que emerge como forma de garantir que, mesmo dentro de um intenso sistema de exploração e opressão que tende à desumanização, se produzam saberes, vínculos, afetos, solidariedade e luta pela liberdade. A resistência concretiza-se, portanto, com a manutenção, a reelaboração e a construção de uma cultura, religião e sociabilidade que continham valores que permitiam aos negros e às negras não perderem elementos de identidade com 


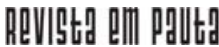

\} LUTAS E RESISTÊNCIAS - SOARES, M. R.P. \}

DOI: $10.12957 /$ REP.2020.52007

o continente de origem, assimilando outros aspectos culturais possíveis dentro do contexto da escravidão. Esta resistência ocorreu em espaços diversos, inclusive nas senzalas, mas os quilombos foram, sem dúvida, um território importante para suas elaborações. Sem a oposição e resistência à escravidão não haveria o que chamamos de cultura afro-brasileira.

Os quilombos representaram e ainda representam uma importante forma de organização social, política, cultural e territorial do povo negro brasileiro (MOURA, 1992; 1993), bem como um modo de resistência ao genocídio dos povos escravizados nestas terras e um grito de liberdade. Além deles, as insurreições e as revoltas organizadas pela tomada do poder político - como os levantes dos negros malês (muçulmanos), na Bahia (entre 1807 e 1835), e a Balaiada (1839), no Maranhão - também constituíram formas de luta contra a escravidão, para citarmos alguns exemplos.

Era a luta em busca da liberdade, dentre outras ações, que tornava possível ao negro escravizado resgatar sua condição de indivíduo/sujeito em contraposição à sua mercantilização. Portanto, como indica Moura (1993, p. 17), "o corpo do escravo era comparado ao dos animais, violentado, mutilado e espancado até a morte. Somente através do espírito de rebeldia, da luta e da reelaboração de comunidades livres ele conseguia a sua reumanização".

Com o fim oficial da escravidão não foram criadas políticas que conferissem direitos aos negros recém-libertos, nem tampouco que lhes possibilitassem qualquer reparação aos anos de trabalho forçado e à violência a que foram submetidos. Esta ausência de reparação e o projeto genocida do Estado brasileiro ${ }^{2}$ estão na base da questão étnico-racial.

\section{A questão étnico-racial no Brasil pós-escravidão}

O Brasil foi o último país das Américas a abolir a escravidão. É importante, porém, observar as condições criadas para a "libertação". Uma delas é a Lei de Terras, de 1850, que estabeleceu a compra como única forma de direito à terra, restringindo as possibilidades de acesso a ela por trabalhadores pobres, recém-libertos e seus descendentes (THEODORO, 2008) ${ }^{3}$. A abolição, assim, foi resultado de uma confluência de elementos, como o aprofundamento da luta dos negros; as pressões políticas dos movimentos abolicionistas; o medo dos senhores de uma revolução como a de São Domingos (Haiti - 1791); o aumento do número de quilombos e dos gastos do Estado para destruí-los; a entrada, cada vez maior, de força de trabalho imigrante no país; e a incompatibilidade do desenvolvimento

\footnotetext{
${ }^{2}$ Ver: Abdias Nascimento (2017).

${ }^{3}$ Os conflitos no campo brasileiro têm relação direta com este processo de apropriação das terras e não reconhecimento dos direitos de trabalhadores rurais, quilombolas e indígenas que constroem relações com o território diferentes das estabelecidas na compra e venda.
} 


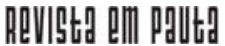

\} LUTAS E RESISTÊNCIAS - SOARES, M. R. P. \}

DOI: $10.12957 /$ REP.2020.52007

do capitalismo com a escravidão nas Américas a partir de então. É inegável, nesse contexto, a contribuição da luta quilombola e das insurreições negras para o fim da escravidão.

Com o fim oficial desse sistema, os quilombos formados pelas fugas dão lugar a outro tipo de organização, que prioriza a luta pela permanência (aquilombamento) dos recém-libertos em áreas rurais próximas às fazendas onde foram escravizados ou mesmo em áreas do perímetro urbano, como nos indica Andrelino Campos (2007) no livro Do quilombo à favela. Nesse texto, ele analisa as favelas como espaços transmutados e resultados da incorporação do território quilombola pelas cidades.

A "libertação dos escravos", mesmo sendo uma confluência de diversos elementos, não rompeu com os padrões socioculturais dominantes. Não há uma incorporação planejada dos recém-libertos às novas relações de trabalho, nem tampouco uma desconstrução de valores racistas. Para Azevedo (1987), o pensamento, amplamente difundido na época, de que os negros em tal condição eram inaptos ao novo regime de trabalho por não conhecerem regras e relações inerentes a este e por estarem irremediavelmente habituados a relações paternalistas e de submissão foi construído como uma ideologia racial. Objetivava assegurar a exclusão dessa parcela significativa da população de postos de trabalho mais qualificados e mesmo justificar o descompromisso do Estado ou dos antigos "senhores" com os libertos. Nota-se, portanto, que,

Não apenas se observou a continuidade dos fenômenos do preconceito e da discriminação racial, como esses foram fortalecidos com a difusão das teses do chamado 'racismo científico'. A adoção pela elite brasileira, de uma 'ideologia racial' teve início nos anos de 1870, tendo se tornado amplamente aceita entre as décadas de 1880 e 1920. A disseminação das teses racistas no Brasil e sua reconstrução na forma de uma ideologia racial ocorreu assim, no período final da escravidão, quando estava em curso o processo de adaptação da sociedade à mudança do status jurídico dos negros. (JACCOỦD, 2008, p. 51).

Por outro lado, com o advento da República, o projeto de nação idealizado pela "elite" brasileira não deixa lugar para o negro, considerandoo um entrave para qualquer desenvolvimento e modernização do país. Assim, a teoria do branqueamento, como um "aprimoramento racial" do povo brasileiro, domina a cena política e influencia "decisões públicas das últimas décadas do século XIX, contribuindo efetivamente para o aprofundamento das desigualdades no país, sobretudo, ao restringirem as possibilidades de integração da população de ascendência africana" (JACCOUD, 2008, p. 53).

A partir de 1930, passa a vigorar, nos debates e projetos políticos, um pensamento racial ancorado na afirmação da dimensão positiva da 


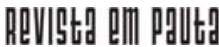

\} LUTAS E RESISTÊNCIAS - SOARES, M. R. P. \}

DOI: 10.12957/REP.2020.52007

mestiçagem: a chamada democracia racial, que tem em Gilberto Freyre seu principal expoente e se configura como pensamento hegemônico até a década de 1980. Cabe ressaltar que, "se a democracia racial afirma-se como deslegitimadora da hierarquia social ancorada na identificação racial, ela não deixa de fortalecer o ideal do branqueamento ao promover a mestiçagem e seu produto, o mulato" (JACCOUD, 2008, p. 55).

Ao conjunto de estratégias ancoradas em ideologias raciais adotadas pela classe dominante e pelo Estado brasileiro sob a roupagem de um projeto de desenvolvimento para a nação Abdias Nascimento (2017) chama de genocídio. Nestes termos, o autor denuncia o "genocídio do negro" como uma estratégia social e política implementada contra o povo negro tanto pelo extermínio do corpo, quanto pelo "branqueamento da raça" e "embranquecimento cultural"4 (NASCIMENTO, 2017, p. 83).

$\mathrm{Se}$, como ideologia, a democracia racial escamoteou o racismo no Brasil por muitas décadas, as expressões da questão social brasileira sempre foram atravessadas pelas desigualdades raciais e trazem elementos suficientes para demonstrar o lugar que o negro ocupava nos índices de desigualdades sociais, revelando que o capitalismo não só não superou as desigualdades raciais, como também utilizou o racismo como mais um instrumento na exploração do trabalho.

No período da República Velha, as manifestações da questão social eram tratadas como caso de polícia (SANTOS, 2012), assim como a existência do negro, já que este era visto como "vagabundo" e "desocupado", e não como trabalhador. Mesmo quando o Estado passa a responder à questão social de outra forma, preservando direitos sociais e regularizando os contratos de trabalho, as profissões e os sindicatos (SANTOS, 2012), a partir de 1930, não se observa uma mudança nos determinantes étnico-raciais como constitutivos das expressões da questão social brasileira.

Com a industrialização nacional, "a posição relativa dos negros e brancos na hierarquia social não foi substancialmente alterada com o processo de crescimento e modernização econômica" (JACCOUD, 2008, p. 54). O que se observa é que "A industrialização não eliminou a raça como fator organizador de relações sociais e oportunidades econômicas, nem reverteu a subordinação social das minorias raciais" (JACCOUD, 2008, p. 54).

Em que pesem as contribuições de intelectuais e de movimentos negros na denúncia das desigualdades raciais e do racismo, ainda vigorava, na sociedade da época, a ideologia da democracia racial, e a discriminação era naturalizada. Por outro lado, o não reconhecimento das desigualdades raciais pelo Estado não permitia que se incorporasse esta questão na ela-

\footnotetext{
${ }^{4}$ Ver: Racismo e sexismo na cultura brasileira de Lélia Gonzales (1984), sobre o lugar da mulher negra no processo de miscigenação, fundamentado e apoiado na exploração sexual, que trará marcas profundas na forma como a cultura do machismo se expressa em nossa sociedade, atravessada pela questão étnico-racial.
} 


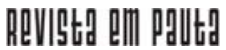

\} LUTAS E RESISTÊNCIAS - SOARES, M. R. P. \}

DOI: $10.12957 /$ REP.2020.52007

boração das políticas públicas, como uma problemática a ser enfrentada pela gestão do país.

É somente com a Constituição Federal de 1988 que direitos sociais à população negra são reconhecidos em lei, fruto de uma mobilização do movimento negro e de organização de segmentos da sociedade civil em torno da defesa e garantia de direitos sociais e políticos. Outra conquista legal, também expressa nessa Carta Magna, é a definição da prática do racismo como crime inafiançável e imprescritível (artigo 5oㅡㄹ parágrafo XLII). O reconhecimento desse ato como ilegal abre, no país, espaço para o debate público das ações afirmativas a partir de 1990, mas somente a partir de 2000 criam-se políticas afirmativas direcionadas aos negros no Brasil. É com essa Constituição, a partir da mobilização do movimento negro, que são assegurados, em lei, direitos quilombolas, que passam a pautar parte da luta contemporânea destes sujeitos, especialmente em torno do território.

Ressalta-se que território, aqui, é entendido como o lugar onde a vida acontece, como o espaço sociocultural, político e geográfico que comporta as relações entre os sujeitos. O território para os quilombolas é mais do que a terra com o que se pode produzir e extrair dela; envolve relações de afeto, pertencimento e reprodução social; inclui espaços sagrados, como rios, matas virgens, cachoeiras, pedreiras, habitats de "encantados", de "entidades", de "visagens"; lugares que não podem ser medidos, mensurados, por isso não cabem numa relação de compra e venda.

\section{A luta quilombola contemporânea}

É neste contexto de luta dos movimentos sociais e, especificamente, do movimento negro, que é assegurado, na Constituição de 1988, como ato das disposições constitucionais transitórias, no Art. 68, o reconhecimento do direito das terras quilombolas aos seus ocupantes: "Aos remanescentes das comunidades dos quilombos que estejam ocupando suas terras é reconhecida a propriedade definitiva, devendo o Estado emitirIhes os títulos respectivos ${ }^{5 \prime \prime}$ (BRASIL, 1988, n. p.).

Ao mesmo tempo em que o direito legal ao território demarca uma conquista jurídica, explicita as bases da luta de classes envolvendo quilombolas no campo. A disputa em torno do território e a resistência frente ao avanço predatório do capital impõem aos quilombolas a necessidade de enfrentarem um longo, difícil e complexo processo de titulação,

\footnotetext{
${ }^{5}$ A titulação definitiva do território quilombola, que garante a propriedade coletiva é hoje feita pelo Incra. Este processo se inicia com a autodeclaração quilombola e solicitação de certificação junto a Fundação Cultural Palmares, seguido da elaboração e publicação do Relatório Técnico (de forma geral com informações socioculturais, ambientais, econômicas e históricas da comunidade); publicação de portaria de reconhecimento dos limites territoriais; decretos de desapropriação, em caso de haver imóveis privados no território e finalmente a titulação. Cada uma destas etapas é complexa, demorada, envolve articulação interna e externa da comunidade, além de recursos para serem realizadas.
} 


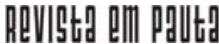

\} LUTAS E RESISTÊNCIAS - SOARES, M. R.P. \}

DOI: $10.12957 /$ REP.2020.52007

que passa por décadas até se efetivar (quando se efetiva) e provoca um enfrentamento político, que muitas vezes acaba em mortes. A luta pelo território quilombola tem várias facetas, dá-se, sobretudo, no enfrentamento de violências diversas, na resistência em permanecer e produzir quando fazendeiros, grandes empresas e o próprio Estado, através de seu braço armado, ameaçam a vida de militantes e de seus familiares.

Em 2003, o Decreto no 4.887 promulgado em 20 de novembro tinha como finalidade regulamentar o processo referente à identificação, reconhecimento, delimitação, demarcação e titulação das terras ocupadas por remanescentes dos quilombos. No seu Art. $2^{\circ}$, define estas comunidades como "Os grupos étnico-raciais, segundo critérios de autoatribuição, com trajetória histórica própria, dotados de relações territoriais específicas, com presunção de ancestralidade negra relacionada com a resistência à opressão histórica sofrida" (BRASIL, 2003, n. p.).

A partir da Constituição Federal de 1988, portanto, a luta quilombola pelo território entra na pauta política, mesmo que de forma marginalizada. Em termos de conquistas reais, entretanto, pouco se avançou, e o reconhecimento destas comunidades deu-se, sobretudo, no âmbito cultural, por meio da Fundação Cultural Palmares, à qual cabe a atribuição de certificação de reconhecimento das comunidades quilombolas, a partir da autoatribuição.

Atualmente existem, segundo dados da Fundação Cultural Palmares $(F C P, 2019)^{6}, 3.271$ comunidades remanescentes de quilombos reconhecidas. Destas comunidades, 2.729 possuem certificação da Fundação; 191 estão com certificação em andamento (em análise técnica); e 38 estão aguardando visita técnica. Para a Coordenação Nacional de Articulação das Comunidades negras Rurais Quilombolas (Conaq), estima-se em 6.000 o número de quilombos no Brasil (CONAQ; TERRA DE DIREITOS, 2018).

Dados do Ministério do Desenvolvimento Social (BRASIL, 2013) indicam a quantidade de comunidades quilombolas por município que recebem auxílio Bolsa Família. Em 1.211 municípios, são 4.520 comunidades quilombolas, com uma estimativa de 109.071 famílias beneficiadas pelo programa7. Conforme detalha Almeida (2018, p. 26-27),

Das 80 mil famílias quilombolas do Cadastro Único, sistema que serve de banco de dados para programas sociais, o documento indicou que $74,7 \%$ viviam em estado de extrema pobreza. O relatório também apontou que os quilombolas têm menos acesso a serviços básicos como saneamento e energia elétrica, quando comparados ao restante da população. Entre os quilombolas, 48,7\% deles vivem em casas

\footnotetext{
${ }^{6}$ Disponível em: www.palmares.gov.br Acesso em: 6 jun. 2019.

${ }^{7}$ Em 2004 foi lançado, no governo Dilma, o Programa Brasil Quilombola, que tinha como objetivo consolidar os marcos da política de Estado para as comunidades quilombolas. O programa, vinculado a Seppir, reconhecia a situação de vulnerabilidade social das comunidades quilombolas indicando que $74,4 \%$ destas estavam abaixo da linha de extrema pobreza.
} 


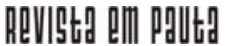

\} LUTAS E RESISTÊNCIAS - SOARES, M. R. P. \}

DOI: $10.12957 /$ REP.2020.52007

com piso de terra batida, 55,21\% não têm água encanada, 33,06\% não têm banheiro e 15,07\% deles possuem esgoto a céu aberto. Há, ainda, um alto índice de analfabetos: 24,81\% deles não sabem ler e, em 2013, a taxa de analfabetismo dentro das comunidades quilombolas era quase três vezes mais alta do que a média nacional, já que a Pesquisa Nacional por Amostras de Domicílio (PNAD) indicava 9,1\% para o país.

De aproximadamente 6.000 comunidades quilombolas do Brasil, apenas 220 possuem o título da terra, somando os emitidos pelo Instituto Nacional de Colonização e Reforma Agrária (Incra), Fundação Cultural Palmares e órgãos estaduais (BRASIL, 2017) ${ }^{8}$. Ou seja, menos de 5\% das comunidades possuem a propriedade coletiva dos territórios.

O que essas informações nos indicam? Que o principal conflito das comunidades quilombolas não está em seu reconhecimento cultural, mas no embate em torno do território e no acesso a políticas públicas. Os conflitos territoriais têm se aprofundado com o avanço predatório do capital (através do agronegócio, grandes empreendimentos, mineração ou mesmo apropriação de saberes e conhecimentos tradicionais).

Além disso, a violência contra quilombolas no Brasil tem aumentado nos últimos anos, resultando inclusive em diversas mortes. O livro Racismo e violência contra quilombos no Brasil (CONAQ; TERRA DE DIREITOS, 2018) traz um levantamento dos anos de 2008 a 2017 e aponta este último como o mais violento do decênio. Em relação ao número de assassinatos, os dados levantados apontam que a Região Nordeste é que tem maior número de ocorrência, seguida do Norte. Identifica-se, ainda, que "o número de assassinatos de 2016 para 2017 cresceu em aproximadamente $350 \%$ ", demonstrando que "o crescimento exponencial das mortes revela uma mudança de conjuntura política e social que agrava o risco da manutenção dos modos de vida e da sobrevivência dos quilombos no país. (CONAQ; TERRA DE DIREITOS, 2018, p. 46).

Reconhecemos que o acesso a direitos básicos por estas comunidades é pauta urgente e que permanece mesmo com a titulação das terras. A questão territorial, entretanto, tem relação direta com a sobrevivência desses povos. A luta pela demarcação e titulação das terras quilombolas é prioritária na maioria das comunidades e se dá contra o capital e suas formas predatórias de acumulação por espoliação (HARVEY, 2005).

Entender a luta quilombola contemporânea a partir da dialética capital/trabalho é importante para sairmos da dimensão culturalista de apreensão da realidade dos quilombos no Brasil, mas não podemos restringir nossa análise apenas a esta relação. Neste contexto, há que se observar outras dimensões constitutivas das comunidades e suas lutas, como a cultura, a ancestralidade, o lugar do simbólico, dos afetos, da religiosidade, dentre

${ }^{8}$ Disponível em: www.incra.gov.br/quilombola. Acesso em: 5 nov. 2017 (BRASIL, 2017). 


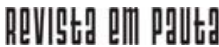

\} LUTAS E RESISTÊNCIAS - SOARES, M. R.P. \}

DOI: $10.12957 /$ REP.2020.52007

outros elementos, sem os quais não entenderemos as formas de resistência e luta destes sujeitos.

Compreender a força de organização, de resistência e de luta que os quilombos representaram no Brasil Colônia e que representam atualmente, bem como as suas estratégias pela permanência e resistência em seus territórios, pode significar, para as diversas organizações da classe trabaIhadora, não só uma referência, mas uma forma de iluminar a luta presente.

\section{Considerações finais}

Com uma população de 55,8\% autodeclarada negra ${ }^{9}$, o Brasil é um país onde o racismo e as questões étnico-raciais estruturam as expressões das desigualdades sociais, da exploração e opressão. São os negros os encarcerados atualmente no país (mais de $60 \%$ da população carcerária nacional é negra ${ }^{10}$ ); os que mais morrem de homicídio $(75 \%$ das vítimas de homicídios no país são negras ${ }^{11}$ ); e os que mais cometem suicídio ( $45 \%$ maior entre jovens negros do que entre brancos, em 2016 ${ }^{12}$ ), evidenciando um genocídio da juventude negra brasileira.

A inserção do debate e os estudos da questão étnico-racial na formação em Serviço Social e nas práticas interventivas constituem um fortalecimento em termos de implementação de um projeto profissional antirracista e comprometido com a emancipação humana. Por outro lado, há que se considerar também o racismo que assistentes sociais sofrem no exercício profissional, conforme demonstra pesquisa realizada pelo ConseIho Regional de Serviço Social de São Paulo - 9a Região (no âmbito da campanha de gestão do conjunto CFESS/Cress Assistentes sociais no combate ao racismo ${ }^{13}$ ), o que consiste em mais um elemento importante para que este debate seja priorizado pela categoria (FREIRE, 2019).

Neste sentido, consideramos que, dentro do estudo da questão étnico-racial no Brasil, recomendado pela Abepss no documento Subsídios para o debate sobre a questão étnico-racial na formação em Serviço Social (ELPIDIO; ROCHA, 2018), é importante a apropriação da discussão histórica e atual dos quilombos brasileiros, bem como o desenvolvimento de pesquisa e extensão nessa área, principalmente em uma conjuntura em que conquistas, em termos de direitos dos trabalhadores e de grupos subalternizados

\footnotetext{
${ }_{9}^{9}$ Disponível em: https://www.ibge.gov.br/estatisticas/sociais/populacao/25844-desigualdades-sociais-por-cor-ouraca.html?=\&t=resultados. Acesso em: 19 maio. 2020.

${ }^{10}$ Levantamento Nacional de informações penitenciarias, de junho de 2016. Ministério da Justiça e Segurança Pública e Depen. Disponível em: <http://depen.gov.br/DEPEN/noticias-1/noticias/infopen-levantamento-nacional-deinformacoes-penitenciarias-2016/relatorio_2016_22111.pdf> Acesso em: 28 maio. 2019.

${ }^{11}$ Segundo o Atlas da Violência 2019 (CERQUEIRA, 2019).

${ }^{12}$ Dados do Ministério da Saúde. Disponível em: ttps://www.cartacapital.com.br/sociedade/jovens-negros-sao-maioriaem-casos-de-suicidio-no-brasil/. Acesso em: 02 jul. 2019.

${ }^{13}$ Disponível em: <ttps://almapreta.com/editorias/realidade/pesquisa-revela-que-racismo-e-recorrente-no-servicosocial. >cesso em: 12 jun. 2019.
} 


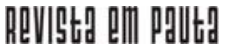

\} LUTAS E RESISTÊNCIAS - SOARES, M. R. P. \}

DOI: 10.12957/REP.2020.52007

como quilombolas e indígenas, vêm sendo ameaçadas com o avanço do conservadorismo e da implementação de uma política ultraliberal de um governo com traços fascistas. 


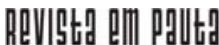

\} LUTAS E RESISTÊNCIAS - SOARES, M. R.P. \}

DOI: $10.12957 /$ REP.2020.52007

\section{Referências}

ABEPSS. Diretrizes Gerais para o curso de Serviço Social. Rio de Janeiro, 1996. Disponível em: http://www.abepss.org.br/arquivos/textos/ documento_201603311138166377210.pdf. Acesso em: 3 maio 2019.

ALMEIDA, M. de. Territórios de afetos: práticas femininas antirracistas nos quilombos contemporâneos do Rio de Janeiro. Tese (Doutorado em História) - Instituto de Filosofia e Ciências Humanas, Unicamp, Campinas, 2018.

AZEVEDO, C. M. M. Onda negra medo branco: o negro no imaginário das elites, séc. XIX. São Paulo: Paz e Terra, 1987.

BRASIL. Constituição da República Federativa do Brasil. Brasília, DF: Senado Federal, 1988.

BRASIL. Decreto no 4.887, de 20 de novembro de 2003. Regulamenta o procedimento para identificação, reconhecimento, delimitação, demarcação e titulação das terras ocupadas por remanescentes das comunidades dos quilombos de que trata o art. 68 do Ato das Disposições Constitucionais Transitórias. Diário Oficial da União, n. 227, 2003.

BRASIL. Incra. Quilombolas. [20-?]. Disponível em: http:// www.incra.gov.br/quilombola. Acesso em: 22 jun. 2017.

BRASIL. Ministério de Desenvolvimento Social e Combate à Fome. Guia de cadastramento de famílias quilombolas: cadastramento para programas sociais. Agência Brasil/Fundação Cultural Palmares, 2013.

CAMPOS, A. Do quilombo à favela: a produção do "espaço criminalizado" no Rio de Janeiro. Rio de Janeiro: Bertrand Brasil, 2007.

CERQUEIRA, D. et al. Atlas da violência 2019. Rio de Janeiro: Ipea, 2019. CONAQ; TERRA DE DIREITOS. Racismo e violência contra quilombos no Brasil. Curitiba: Terra de Direitos, 2018.

ELPIDIO, M. H.; ROCHA, R. Subsídios para o debate sobre a questão étnicoracial na formação em Serviço Social. Temporalis, Brasília, n. 36, jul./dez. 2018.

FCP. Fundação Cultural Palmares. Quilombos. 2019. Disponível em: www.palmares.gov.br. Acesso em: 6 jun. 2019.

FREIRE, S. Pesquisa revela que racismo é recorrente no Serviço Social. Alma Preta, 10 jun. 2019. Disponível em: https://almapreta.com/editorias/ realidade/pesquisa-revela-que-racismo-e-recorrente-no-servico-social. Acesso em: 12 jun. 2019.

GONZALES, L. Racismo e sexismo na cultura brasileira. Revista Ciências Sociais Hoje, 1984. 


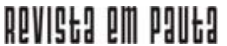

\} LUTAS E RESISTÊNCIAS - SOARES, M. R. P. \}

DOI: $10.12957 /$ REP.2020.52007

HARVEY, D. O novo imperialismo. São Paulo: Edições Loyola, 2005.

IAMAMOTO, M. V. O Serviço Social na contemporaneidade: trabalho e formação profissional. São Paulo: Cortez, 2009.

IANNI, O. Escravidão e racismo. São Paulo: Hucitec, 1978.

JACCOUD, L. Racismo e república: o debate sobre o branqueamento e a discriminação racial no Brasil. In: THEODORO, M. (Org.). As políticas públicas e a desigualdade racial no Brasil: 120 anos após a abolição. Brasília: Ipea, 2008.

LOURENÇO, M. Jovens negros são maioria em casos de suicídio no Brasil. Carta Capital, 6 jun. 2019. Disponível em: https://www.cartacapital.com.br/ sociedade/jovens-negros-sao-maioria-em-casos-de-suicidio-no-brasil/. Acesso em: jul. 2019.

MARX, K. O capital: crítica da economia política. Livro I, vol. 2. Rio de Janeiro: Civilização Brasileira, 1998.

MOURA, C. História do negro brasileiro. São Paulo: Editora Ática, 1992.

MOURA, C. Quilombos: resistência ao escravismo. São Paulo: Editora Ática, 1993.

NASCIMENTO, A. O genocídio do negro brasileiro: processo de um racismo mascarado. São Paulo: Perspectiva, 2017.

QUIJANO, A. Colonialidade do poder, eurocentrismo e América Latina. In: LANDER, E. A colonialidade do saber: eurocentrismo e ciências sociais. Perspectivas latino-americanas. Buenos Aires: Clacso, 2005.

ROCHA, R. da F. A questão étnico-racial no processo de formação em serviço social. Serviço Social e Sociedade, São Paulo, n. 99, jul./set. 2009.

SANTOS, J. S. "Questão social": particularidades no Brasil. São Paulo: Cortez, 2012.

THEODORO, M. A formação do mercado de trabalho e a questão racial no Brasil. In: THEODORO, M. (org.). As políticas públicas e a desigualdade racial no Brasil: 120 anos após a abolição. Brasília: Ipea, 2008.

DOI: $10.12957 /$ rep.2020.52007

Recebido em 29 de junho de 2019.

Aprovado para publicação em 05 de fevereiro de 2020.

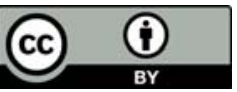

A Revista Em Pauta: Teoria Social e Realidade Contemporânea está licenciada com uma Licença Creative Commons Atribuição 4.0 Internacional. 